\title{
Non-epithelial Ovarian Cancer: Elucidating Uncommon Gynaecological Malignancies
}

\author{
STERGIOS BOUSSIOS ${ }^{1}$, GEORGE ZARKAVELIS ${ }^{1}$, ESMERALDA SERAJ ${ }^{1}$, IOANNIS ZERDES ${ }^{1}$, \\ KONSTANTINA TATSI ${ }^{2}$ and GEORGE PENTHEROUDAKIS ${ }^{1}$ \\ ${ }^{1}$ Department of Medical Oncology, Medical School, University of Ioannina, Ioannina, Greece; \\ ${ }^{2}$ Gynaecology Unit, G. Hatzikosta General Hospital, Ioannina, Greece
}

\begin{abstract}
Non-epithelial ovarian cancers (NEOC) are a group of fascinating but uncommon malignancies which can be extremely challenging to treat. Collectively, these tumours only represent 10-15\% of all ovarian cancers and occur in all age groups from childhood to old age. This broad term includes diverse tumours of germ cell origin, sex cord-stromal cell origin, as well as extremely rare types of ovarian cancer, such as small-cell carcinomas and sarcomas, each of which require specialist management. It is imperative that these rare tumours are managed with accurate diagnosis, staging and treatment in order to optimize patient outcomes. The aetiology and molecular origins of each sub-group of NEOC remain poorly understood and international cooperation to facilitate high quality translational research is needed. This review summarizes the published literature on the incidence, clinical presentation, pathology, therapeutic interventions, survival and prognostic factors of each sub-type of NEOC.
\end{abstract}

Non-epithelial ovarian cancer (NEOC) are a group of uncommon, histologically and clinically distinct tumours. The two most frequently diagnosed NEOC are germ cell tumours (GCTs) and sex cord-stromal cell tumours (SCSTs), each of which have several histological sub-types (Table I) (1). Ovarian small cell cancers (hypercalcaemic and nonhypercalcaemic types) and sarcomas are extremely rare and aggressive cancers, with an aggressive clinical course and a generally dismal prognosis.

This article is freely accessible online.

Correspondence to: Dr Stergios Boussios, MD, Ph.D., Department of Medical Oncology, Ioannina University Hospital, Ioannina, Greece. E-mail: stergiosboussios@gmail.com

Key Words: Germ cell tumours, sex cord-stromal tumours, review.
GCTs are diagnosed principally in the first three decades of life (2). In contrast, SCSTs occur in women of all ages but increase in frequency during the fourth and fifth decades of age and patients have a median age at diagnosis of 52 years $(3,4)$. The incidence rates of these two most common subtypes of NEOC also differ by race. GCTs of are more frequent in Asian and African women (5), whereas SCSTs occur more commonly in women of Caucasian background (3). The yearly adjusted incidence rate is approximately 4 per $1,000,000$ and 2 per $1,000,000$ women for GCTs and SCSTs, respectively (6). The aetiology of these tumours remains largely unresolved. Ovarian small cell cancers of hypercalcaemic type affect young women, with a median age of diagnosis of 24 years (7). Small cell ovarian carcinomas of pulmonary type affects older women (median age 59 years) (8); with a clinical course and prognosis most similar to that of small cell lung cancer. Sarcomas of the ovary are extremely rare and heterogenous tumours including primary ovarian fibrosarcoma, angiosarcoma and rhabdomyo-sarcoma. The International Federation of Gynecology and Obstetrics (FIGO) staging system for epithelial ovarian cancer is also adopted for NEOC, however, due to high chemotherapy sensitivity and good prognosis of GCTs, the recommended surgical staging is much less aggressive.

Treatment of NEOC, as a group, should be on the basis of sound oncological principles. Due to the rarity of NEOC, randomised trials for assessing the relative benefits of different treatment modalities are extremely challenging. Cooperation is also required to further our knowledge of the molecular events which lead to NEOC and aid identification of novel drug targets.

The main purpose of this review was to show how an interdisciplinary model of case management, involving representatives from pathology, radiation, medical and gynecology-oncology can be invaluable in optimizing patient outcomes. 


\section{GCTs}

These tumours occur principally in children and young women aged 10-30 years, with a mean age in the teenage years. GCTs are the most common ovarian neoplasm in women aged $<30$ years $(9)$.

Clinical presentation. Presenting signs and symptoms can include abdominal pain with a palpable pelvic-abdominal mass in the majority of patients (85\%), abdominal distension (35\%), fever $(10 \%)$, and vaginal bleeding $(10 \%)$. A small proportion of patients exhibit symptoms of pregnancy or precocious puberty, related to $\beta$-human chorionic gonadotropin ( $\beta$-hCG) production by the tumour (10). The disease is unilateral in most patients with early disease and the presence of bilateral ovarian involvement suggests dysgerminoma or mixed histology with a predominant dysgerminoma element, of which $10-15 \%$ will involve both ovaries at presentation (11).

Due to the age of patients affected by ovarian GCT, this disease can manifest during pregnancy. The results of a recent study indicated that advanced-stage GCT-complicated pregnancies were an independent prognosticator of decreased maternal survival (12). The timing of oncological intervention and delivery both significantly impacted on the outcomes both of foetal and maternal survival.

Diagnosis. Diagnosis can usually be made on morphological features, and immunohistochemical markers and chromosome $12 \mathrm{p}$ fluorescence in situ hybridisation can be used to confirm the diagnosis in difficult cases. Sal-like protein 4 (SALL4) is a sensitive and specific marker for GCT and is positive in dysgerminomas, yolk sac tumours (YSTs), the germ cell component of gonadoblastoma, embryonal carcinoma, some immature teratomas (13), however, it is also positive in rare alpha-fetal protein (AFP)-producing fetal-type gastric carcinomas (14). OCT3/4, a nuclear transcription factor, also known as POU5F1, is also widely used. In addition, expression of sex determining region Y-box 2 (SOX2) in embryonal carcinoma and primitive neuroectoderm of teratoma has been recently recognised (4).

Many, but not all, GCTs produce serum tumor markers that can aid in the establishment of diagnosis, monitoring during therapy, and have a useful role in post-treatment surveillance. YSTs and choriocarcinoma are characterized by production of AFP and $\beta$-hCG, respectively. Around one-third of immature teratomas will produce AFP, and raised lactate dehydrogenase can be a useful marker in dysgerminomas. Correspondingly, mixed GCT may produce either AFP, $\beta$ $\mathrm{hCG}$, both, or no markers, depending on their composition.

Classification. According to the 2003 WHO classification system, GCT are divided into three categories: primitive GCT, biphasic or triphasic teratoma, and monodermal
Table I. Classification of non-epithelial ovarian cancer (modified from the World Health Organization Histological Classification of Tumours of the Ovary) (1).

Primitive GCT

1. Dysgerminoma

2. YST

3. Embryonal carcinoma

4. Polyembryoma

5. Choriocarcinoma

Biphasic or triphasic teratoma

1. Immature teratoma

2. Mature teratoma

Mixed type (two or more of the above types)

SCST

1. GrCT

a. Adult-type GrCT

b. Juvenile-type GrCT

2. Theca-fibroma group

a. Thecoma

b. Fibroma

c. Fibrosarcoma

d. Sclerosing stromal tumor

e. Signet-ring stromal tumor

3. Sertoli-stromal cell tumor

a. Well-differentiated

b. Of intermediate differentiation, variant with heterologous elements

c. Poorly differentiated (sarcomatatoid), variant with heterologous elements

d. Retiform, variant with heterologous elements

4. SCST of mixed or unclassified cell type

a. Gynandroblastoma (specify components)

b. SCST, unclassified

Metastatic tumours, e.g. Krukenberg

GCT: Germ cell tumours, YST: endodermal sinus tumours, SCST: sexcord stromal tumours, GrCT: granulosa cell tumours.

teratoma and somatic-type tumours associated with dermoid cysts (Table I) (1). This latter group will follow the clinical course of the somatic-type tumour, therefore their treatment should be tailored to the somatic-tumour type rather than the benign germ-cell element.

Like GCT in males, in clinical practice, ovarian GCTs are commonly divided into dysgerminomas (analogously to male seminomas) and non-dysgerminomatous tumours. The latter include the more common YSTs and immature teratomas, as well as the rarer embryonal carcinoma, non-gestational choriocarcinoma, and polyembryoma sub-types. Current approaches to the treatment are summarised in Table II.

\section{Dysgerminomas}

Dysgerminomas account for $30-40 \%$ of ovarian GCT cases, and $20-30 \%$ of ovarian malignancies associated with pregnancy (15). These tumours uncommonly secrete low levels of $\beta$-hCG (from multinucleated syncytiotrophoblastic giant cells), but AFP secretion is not expected with pure dysgerminomas. 
Table II. Management options for of germ cell tumours (GCT).

GCT

\begin{tabular}{lll}
\cline { 2 - 3 } Dysgerminomas & Immature teratomas & Other GCT \\
\hline
\end{tabular}

Stage I

Stage IA

Stage IB/C

Stage II

Stage III and IV
USO with preservation of the contralateral ovary and uterus for fertility purposes with a full staging procedure.

If patient has completed child bearing, TAH-BSO is acceptable.
Observation without adjuvant treatment.

Adjuvant chemotherapy
G1: Observation without adjuvant treatment

G2: Adjuvant treatment may be considered G3: Adjuvant chemotherapy

Adjuvant chemotherapy
Adjuvant chemotherapy

Adjuvant chemotherapy

USO with preservation of the contralateral ovary and uterus for fertility purposes with a full staging procedure. If patient has completed child bearing, TAH-BSO is acceptable.

Adjuvant chemotherapy

USO with preservation of the contralateral ovary and uterus for fertility purposes with a full staging procedure.

If patient has completed child bearing, TAH-BSO is acceptable.

Following maximal surgical debulking, adjuvant chemotherapy is indicated.

Neoadjuvant chemotherapy can be considered for patients with extensive intra-abdominal disease, when initial debulking surgery is not an option.

$\begin{array}{lll}\text { Recurrent tumours } & \text { Chemotherapy } & \text { Chemotherapy } \\ & \text { Radiation therapy in selected circumstances } & \text { Chemotherapy }\end{array}$

USO: Unilateral salpingo-oophorectomy, TAH-BSO: total abdominal hysterectomy and bilateral salpingo-oophorectomy, G: grade.

About $75 \%$ of dysgerminomas are stage I at diagnosis, and bilateral disease is reported in $10-15 \%$ of patients; inevitably leading to surgical challenges to maintain fertility. For patients who present with more advanced disease, spread is most commonly via the lymphatics (15), however, direct extension through the capsule of the ovary and haematogenous spread may also occur.

Approximately 5\% of dysgerminomas are discovered in phenotypic females with abnormal gonads (15). Therefore, pre-menarchal patients with a pelvic mass should have their karyotype determined.

The treatment of patients with dysgerminoma is primarily surgical, including the resection of the primary lesion and surgical staging. To preserve fertility, the contralateral ovary, fallopian tube, and uterus should usually be conserved, even in the presence of metastatic disease because of the exquisite chemotherapy sensitivity of this sub-type. Stage IA pure dysgerminoma can safely be treated with surgery and surveillance alone as the recurrence rate is low $(15-25 \%)$ and patients can be successfully salvaged with combination chemotherapy at relapse, thereby avoiding chemotherapy for the majority of women. The role of adjuvant chemotherapy for stage 1b-1c disease remains controversial (16), although data supporting surveillance alone in paediatric patients are encouraging (17).

\section{Immature teratomas}

Pure immature teratomas are the second most common subtype, and may also be mixed with other sub-types. Immature teratomas are highly chemotherapy-sensitive and contralateral involvement is rare (11), permitting fertilitysparing surgery, with or without adjuvant chemotherapy for most patients. The requirement for chemotherapy depends upon tumour stage and grade: Patients with stage 1A grade 1 immature teratomas can be safely spared chemotherapy. In contrast, chemotherapy is recommended for patients grade 2 or 3 tumours of any stage and stage $\geq 1$ a tumours irrespective of tumour grade (16).

\section{YST}

YSTs, formerly known as endodermal sinus tumours, are the third most common malignant ovarian GCTs (18). Five patterns of YST have been described, comprising microcystic, endodermal sinus, solid, alveolar-glandular, and polyvesicular vitelline sub-types. Mixed histological patterns have been described but co-existence with an epithelial malignant component is rare and may actually represent adenocarcinomas with aberrant YST differentiation. This is supported by their occurrence in older patients, an aggressive 
clinical course and poor prognosis. For rare patients with mixed epithelial/YST, adjuvant platinum-based chemotherapy, such as carboplatin and paclitaxel, which has activity against both components (19).

YSTs typically secrete AFP and positive staining for AFP is present in $>75 \%$. Other immunohistochemical markers that are typically positive in YST include SALL4 (13) which is useful in distinguishing YST from ovarian clear cell adenocarcinoma, and glypican-3, which is more sensitive than AFP for YST, but less specific (20).

YSTs are confined to one ovary in about half of patients and bilateral ovarian involvement is rare. Prior to introduction of combination chemotherapy, the prognosis was poor even for patients with stage I disease. Surveillance with AFP monitoring and regular imaging has been investigated as a strategy to avoid adjuvant chemotherapy in paediatric patients, but over half of all patients experienced relapse. The majority were salvaged with chemotherapy (17) but the applicability of this strategy to adult patients has not yet been determined.

\section{Surgical approaches}

I. Primary surgery. a. Non-fertility-sparing surgery: In all postmenopausal women and pre-menopausal patients with bilateral ovarian involvement, abdominal hysterectomy and bilateral salpingo-oophorectomy (TAH-BSO) with careful surgical staging is usually recommended. Fertility-sparing surgery may be feasible in pre-menopausal patients with bilateral disease, if followed by adjuvant chemotherapy.

b. Fertility-sparing surgery: Unilateral salpingooophorectomy (USO) with preservation of the contralateral ovary and the uterus is now considered to be adequate surgical treatment for the majority of pre-menopausal patients with GCT. In children and adolescents, an Intergroup study reported excellent survival for all stages despite limiting surgical treatment to USO in the majority of cases. Support for such an approach in adults arises from experiential evidence: There was no detrimental effect on prognosis in a study of 182 patients who underwent fertility-sparing surgery for radiologically stage I tumours (21). For some patients, even cystectomy of the involved ovary may be adequate surgical treatment, but there are currently insufficient data to support this approach routinely. If proven to be safe, this could be especially valuable for pre-menopausal patients with bilateral disease in whom fertility preservation is desired.

c. Comprehensive surgical staging: Comprehensive surgical staging (comprising of full inspection and biopsies of the peritoneal surfaces, inspection of para-aortic and pelvic lymph nodes and infracolic omentectomy in addition to either USO or TAH/BSO) remains the gold standard (22). Biopsy of a macroscopically normal contralateral ovary is not required for fertility-sparing procedures, but endometrial biopsy is commonly performed if TAH is not planned. A commonly encountered clinical dilemma is whether surgical restaging after emergency USO is necessary. Postoperative computed tomography (CT) imaging followed by adjuvant chemotherapy for patients with normal scans and tumour markers is a pragmatic approach for patients with high of risk tumours. For unstaged tumours with good prognosis (dysgerminoma or grade 1 immature teratoma), surveillance alone is an option for those with normal tumour markers and postoperative imaging. However, patients with persistent disease on CT or raised tumour markers should ideally have staging surgery, as they could avoid adjuvant chemotherapy if stage 1A disease is confirmed (23). Avoidance of further surgery but proceeding with adjuvant chemotherapy with careful tumour marker monitoring is an alternative.

d. Cytoreductive surgery: In advanced disease, radical cytoreductive surgery should not include non-gynaecological organ resection, as adjuvant chemotherapy obviates the need for such morbid surgery for the majority of patients.

II. Secondary surgery. a. Salvage surgery: Second-look surgery should be considered for patients with incompletely resected tumour that contains teratoma elements (24). In practice, a second resection is generally limited to patients with residual immature teratoma following adjuvant chemotherapy, or growing teratoma syndrome (25).

Adjuvant treatment. Prior to the advent of combination chemotherapy, the prognosis for patients with GCT was bleak. Platinum-based regimens have been the gold standard treatment for more than a decade and the bleomycin, etoposide, and cisplatin (BEP) regimen is most widely used. The optimal number of cycles of BEP remains unresolved, but 3 cycles will prevent recurrence in the majority of patients with completely resected disease. Four to five cycles (omitting to bleomycin after cycle 3 to minimise lung toxicity) are recommended for patients with macroscopic residual disease (16), although arguably this should be continued for up to six cycles in patients with evidence of ongoing radiological or biochemical response.

The standard BEP regimen is a 5-day course of daily cisplatin and etoposide with additional weekly bleomycin doses on days 1, 8 and 15. An alternative more convenient 3-day regimen has been investigated in randomised studies in male GCT and in non-randomised trials in ovarian GCT and appears to be both safe and effective, with a $96 \%$ 5-year disease-free survival reported (26).

Recurrent disease. Most recurrences occur within 24 months of initial GCT diagnosis and the most common sites of relapse are the peritoneal cavity and retroperitoneal lymph nodes (15). There is no internationally accepted standard treatment for relapse of ovarian GCT and the approach is largely based on data in male GCT. The most commonly employed salvage 
regimens therefore include vinblastine, ifosfamide, and cisplatin; etoposide, ifosfamide, and cisplatin; and paclitaxel, ifosfamide, and cisplatin (27). The salvage rate for chemotherapy in patients with ovarian GCT is approximately $50 \%$ (11). Depending upon the site and distribution of relapse, radiotherapy may be an effective alternative, but this must be balanced against the morbidity including loss of fertility if abdomino-pelvic radiation is required. Retrospective reports suggest a possible role for secondary cytoreductive surgery in selected patients with recurrent GCT. Ideal candidates for such consideration would be those with limited sites of recurrent tumour. In particular, patients with relapsed dysgerminoma that was incompletely staged at diagnosis may be cured by this approach (28).

Prognosis. Despite the rapid rate of growth associated with malignant GCT, the majority (60-70\%) are diagnosed at an early stage, with cure rates now approaching $100 \%$. Even in advanced-stage (III-IV) disease, at least $75 \%$ of patients will be cured. In addition to advanced FIGO stage, poor prognostic factors may include residual tumour after salvage surgery, raised tumour markers at diagnosis, nondysgerminoma histology and age $>40$ years at diagnosis (29).

Late effects of therapy of GCT. With such an excellent prognosis, especially for women with early-stage disease, deintensification of treatment and avoidance of late effects is an important area of research.

The majority of young women who are treated with fertility-sparing surgery and combination chemotherapy for ovarian GCT may expect recovery of ovarian function, usually within a few months after treatment. Fertility seems to be only marginally affected by treatment, with many reports of successful pregnancies (30). The rate of miscarriages is within the expected range for the general population, however, the congenital malformation rate in offspring of previous GCT patients is slightly higher than in the general population (31). Premature menopause is more common following chemotherapy (32), therefore these patients must be advised to avoid significant delay starting a family, if possible. Extrapolating data from breast cancer trials and prescribing gonadotropin-releasing hormone analogues with chemotherapy is a reasonable approach to reducing the rate of premature menopause and protecting fertility (33).

The risk of a second primary cancer is a significant concern following curative treatment for ovarian GCT. The risk of malignancy appears to correlate with the cumulative dose of etoposide, a factor which must be taken into consideration when determining the number of cycles of BEP/etoposide and cisplatin chemotherapy to deliver (34). Research into de-intensification of chemotherapy for highrisk patients and avoidance of adjuvant chemotherapy altogether for patients with early good prognosis disease remain the most important strategies to minimise the risk of second malignancy.

\section{SCSTs}

SCSTs account for 5-8\% of ovarian malignancies (15). They arise from the sex cords and ovarian stroma and represent a heterogeneous group of neoplasms with variable biological behaviour, clinical presentation and prognosis: Whilst these are generally indolent, slow growing tumours, more aggressive behaviour can be exhibited. Granulosa cell tumours (GrCTs) are the most common sub-type; SertoliLeydig cell tumours (SLCT) and theca cell tumours are rare.

SCSTs can occur over a wide age range, but most commonly present in the 5th and 6th decade of life. Younger age, early-stage and low tumour grade are the most important predictors for improved disease-specific survival for SCST (35).

\section{GrCTs}

Ovarian GrCTs have an incidence of approximately one case per 200,000 women per year (36), representing 2-5\% of all ovarian cancer (4). For the majority of patients presenting with stage I disease, the short-and medium-term prognosis is excellent. However, even early-stage disease frequently recurs but due to the relatively indolent nature of this disease, such recurrences often occur years after the initial treatment, with a resultant 20-year survival rate of $67 \%$ (4).

GrCTs are divided into juvenile and adult types based on clinical presentation and histologic characteristics: The juvenile type accounts for only about $5 \%$ of $\mathrm{GrCT}$ and has a distinctive histological appearance. Histologically, their architecture is often lobulated, Call-Exner bodies are rare, and signs of luteinisation are common (37). Characteristically juvenile GrCT occur in children and young adults, comprising $85 \%$ of GrCT observed before puberty. Immunocytochemically, juvenile GrCT are similar to adult types except around $50 \%$ are positive for expression of epithelial membrane antigen (EMA) (38).

Adult GrCT typically presents during the perimenopausal or early postmenopausal period and occurs only rarely in children and young women (39). Histological features include monomorphic proliferation of uniform cells containing vesicular nuclei and high nuclear to cytoplasmic ratios, with low mitotic rates. A prominent longitudinal nuclear groove is helpful in confirming the diagnosis. There are five subtypes, of which microfollicullar is the most common (40). Forkhead box L2 (FOXL2) mutations are usually present in adult GrCT and rare in juvenile GrCT, aiding diagnosis, especially where the patient's age is outside the usual range (41). 
Table III. Summary of chemotherapy regimens for granulosa cell tumours (GrCT).

\begin{tabular}{|c|c|c|c|c|}
\hline Author & Year of publication & Regimen & Response & Overall RR (\%) \\
\hline Gershenson et al. (71) & 1987 & CAP & $3 / 8 \mathrm{CR}$ & 63 \\
\hline \multirow[t]{2}{*}{ Pecorelli et al. (72) } & 1988 & PVB & $12 / 38 \mathrm{CR}$ & \\
\hline & & & $11 / 38 \mathrm{PR}$ & 60 \\
\hline \multirow[t]{2}{*}{ Zambetti et al. (49) } & 1990 & PVB & $3 / 7 \mathrm{CR}$ & 66 \\
\hline & & & 1/7 PR & \\
\hline \multirow[t]{2}{*}{ Pectasides et al. (73) } & 1992 & CAP & $5 / 10 \mathrm{CR}$ & 60 \\
\hline & & & 1/10 PR & \\
\hline \multirow[t]{2}{*}{ Gershenson et al. (74) } & 1996 & BEP & $2 / 6 \mathrm{CR}$ & 83 \\
\hline & & & $3 / 6 \mathrm{PR}$ & \\
\hline \multirow[t]{3}{*}{ Savage et al. (46) } & 1998 & PVB & $1 / 5 \mathrm{CR}$ & 80 \\
\hline & & & $3 / 5 \mathrm{PR}$ & \\
\hline & & BEP & $1 / 3 \mathrm{PR}$ & 33 \\
\hline \multirow[t]{2}{*}{ Homesley et al. (75) } & 1999 & BEP & 6/38 CR & 26 \\
\hline & & & 4/38 PR & \\
\hline \multirow[t]{2}{*}{ Al-Badawi et al. (76) } & 2002 & CDDP/ADR/CTX/MTX & $1 / 1 \mathrm{CR}$ & 100 \\
\hline & & CDDP/ADR/BLEO/V & $1 / 4 \mathrm{PR}$ & 25 \\
\hline \multirow[t]{3}{*}{ Uygun et al. (77) } & 2003 & CTX/ADR/CDDP & 5/14 CR & \\
\hline & & & 5/14 PR & \\
\hline & & & $4 / 14 \mathrm{SD}$ & 100 \\
\hline \multirow[t]{3}{*}{ Brown et al. (50) } & 2005 & BEP & 6/8 CR & 75 \\
\hline & & $\mathrm{CDDP} / \mathrm{PaC}$ & $2 / 2 \mathrm{PR}$ & 100 \\
\hline & & $\mathrm{Ca} / \mathrm{PaC}$ & $6 / 13 \mathrm{SD}$ & 46 \\
\hline \multirow[t]{2}{*}{ Pectasides et al. (78) } & 2008 & CTX/ADR/CDDP or CDDP/Ep/CTX & $6 / 13 \mathrm{CR}$ & 54 \\
\hline & & BEP & $1 / 1 \mathrm{PR}$ & 100 \\
\hline \multirow[t]{3}{*}{ Pautier et al. (79) } & 2008 & $\mathrm{BEP}$ & 9/20 CR & \\
\hline & & & 9/20 PR & \\
\hline & & & $1 / 20 \mathrm{SD}$ & 95 \\
\hline \multirow[t]{3}{*}{ van Muers et al. (80) } & 2014 & BEP & $1 / 9 \mathrm{CR}$ & \\
\hline & & & $1 / 9 \mathrm{PR}$ & \\
\hline & & & $7 / 9 \mathrm{SD}$ & 100 \\
\hline
\end{tabular}

CAP: Cyclophosphamide, doxorubicin, cisplatin, PVB: cisplatin, vinblastine, bleomycin, BEP: bleomycin, etoposide, cisplatin, CDDP: cisplatin, ADR: doxorubicin, CTX: cyclophosphamide, MTX: methotrexate, BLEO: bleomycin, V: vinblastine, PaC: paclitaxel, Ca: carboplatin, Ep: epirubicin, CR: complete response, PR: partial response, SD: stable disease.

Clinical presentation. The most common presenting symptoms are abnormal uterine bleeding and abdominopelvic pain. Haematoperitoneum may occur uncommonly due to tumour rupture. Pre-menopausal patients may have menstrual irregularities, menorrhagia, intermenstrual bleeding or amenorrhea. The majority of GrCTs produce oestradiol, therefore in juvenile GrCT, $80-90 \%$ of patients under 8 years of age display signs of precocious puberty. Jjuvenile GrCT may also rarely cause virilisation in older patients. In older patients, the symptoms may mimic those of common epithelial ovarian cancer with bloating and altered bowel habit.

Tumor markers. Oestradiol: Although oestradiol is commonly secreted by GrCT, oestradiol levels are not a reliable marker of disease activity (42). Oestradiol is not produced at all in around $30 \%$ of cases due to the lack of theca cells in the tumour stroma.
Inhibin: Inhibin is a dimeric, ovarian glycoprotein hormone consisting of $\alpha$ - and two $\beta$-subunits which give rise to measurable inhibin-A and inhibin-B in the serum, respectively. Inhibin suppresses the synthesis and secretion of pituitary follicle-stimulating hormone. Either or both inhibins, may be secreted by GrCT, although inhibin B is more frequently elevated (43). Inhibin levels typically rise 11 months before radiological progression is evident (3).

Treatment. Surgery: GrCTs are bilateral in only 3\% of patients, therefore fertility-sparing surgery with USO is feasible for stage IA tumours in pre-menopausal patients wishing to retain their fertility. If hysterectomy is not planned then endometrial biopsy is recommended, as a synchronous endometrial cancer is present in about $5 \%$ of cases; and endometrial hyperplasia secondary to excess oestrogen is present in a further $25 \%$ (15). Endometrial carcinomas related to GrCT are usually well-differentiated, 
Table IV. Summary of reported hormonal regimens for granulosa cell tumours.

\begin{tabular}{|c|c|c|c|}
\hline Author & Year of publication & Regimen (no. of patients) & Response \\
\hline Malik et al. (81) & 1991 & $\operatorname{MPA}(n=2)$ & $2 \mathrm{PR}$ \\
\hline \multirow[t]{3}{*}{ Isaacs et al. (82) } & 1992 & $\operatorname{MPA}(n=1)$ & $1 \mathrm{CR}$ \\
\hline & & Tamoxifen $(n=1 *)$ & $1 \mathrm{PD}$ \\
\hline & & Megestrol acetate $(n=1 *)$ & $1 \mathrm{PR}$ \\
\hline \multirow[t]{3}{*}{ Kauppila et al. (83) } & 1992 & Goserelin $(\mathrm{n}=4)$ & $2 \mathrm{PR}$ \\
\hline & & & $2 \mathrm{PD}$ \\
\hline & & Goserelin + tamoxifen $(n=1)$ & $1 \mathrm{PD}$ \\
\hline Maxwell et al. (84) & 1994 & Leuprolide ( $\mathrm{n}=2$ ) & 2 PD \\
\hline \multirow[t]{3}{*}{ Fishman et al. (85) } & 1996 & $7.5 \mathrm{mg}$ Leuprolide acetate $(\mathrm{n}=5)$ & $2 \mathrm{PR}$ \\
\hline & & & $3 \mathrm{SD}$ \\
\hline & & Tamoxifen $(\mathrm{n}=1)$ & $1 \mathrm{SD}$ \\
\hline Briasoulis et al. (86) & 1997 & $160 \mathrm{mg}$ Megestrol acetate $(n=1)$ & $1 \mathrm{PR}$ \\
\hline Crew et al. (87) & 2005 & Leuprolide $(\mathrm{n}=1)$ & $1 \mathrm{SD}$ \\
\hline Ameryckx et al. (88) & 2005 & Ganirelix $(\mathrm{n}=1)$ & $1 \mathrm{PD}$ \\
\hline Hardy et al. (89) & 2005 & Alternating biweekly cycles of megestrol and tamoxifen $(n=1)$ & $1 \mathrm{CR}$ \\
\hline \multirow[t]{3}{*}{ Freeman et al. (90) } & 2006 & Anastrozole $(\mathrm{n}=2)$ & $2 \mathrm{CR}$ \\
\hline & & Leuprolide $(n=2)$ & $1 \mathrm{SD}$ \\
\hline & & & $1 \mathrm{PD}$ \\
\hline \multirow{3}{*}{ Korach et al. (91) } & 2009 & Anastrozole $(n=2)$ & $1 \mathrm{CR}$ \\
\hline & & & $1 \mathrm{PR}$ \\
\hline & & Letrozole $(\mathrm{n}=2)$ & $2 \mathrm{CR}$ \\
\hline Kim et al. (92) & 2009 & $3.75 \mathrm{mg}$ Leuprorelin $(\mathrm{n}=1)$ & $1 \mathrm{PR}$ \\
\hline \multirow[t]{2}{*}{ Teoh et al. (93) } & 2010 & $22.5 \mathrm{mg}$ Leuprolide acetate every three months and $20 \mathrm{mg}$ tamoxifen twice daily $(\mathrm{n}=1)$ & $1 \mathrm{PD}$ \\
\hline & & $40 \mathrm{mg}$ Megestrol acetate orally four times daily for 3 months $(\mathrm{n}=1)$ & $1 \mathrm{PD}$ \\
\hline Abdul Munem et al. (94) & 2012 & Anastrozole $(\mathrm{n}=1)$ & $1 \mathrm{PR}$ \\
\hline Alhilli et al. (95) & 2012 & Letrozole $(\mathrm{n}=1)$ & $1 \mathrm{PR}$ \\
\hline Keskin et al. (96) & 2012 & $11.25 \mathrm{mg}$ Leuprolide every 3 months and $20 \mathrm{mg}$ tamoxifen twice daily $(\mathrm{n}=1)$ & $1 \mathrm{CR}$ \\
\hline Kourie et al. (97) & 2013 & Letrozole $(\mathrm{n}=1)$ & $1 \mathrm{CR}$ \\
\hline
\end{tabular}

MPA: Medroxyprogesterone acetate, CR: complete response, PR: partial response, SD: stable disease, PD: progressive disease. *This patient received two lines of hormonal treatment.

early-stage and associated with a good prognosis. In periand postmenopausal women, TAH, BSO and full staging surgery should be performed. In contrast to GCT, GrCTs are not highly chemotherapy sensitive, so complete debulking surgery is key to improving survival (44). Spread of GrCT is usually local, by direct extension and peritoneal seeding, but may also spread haematogenously to the lungs, liver, and even brain. Metastatic disease at presentation is rare and more commonly develops years after initial treatment.

Radiotherapy: Adjuvant radiotherapy and targeted radiotherapy for oligometastatic but inoperable recurrent disease has been investigated $(45,46)$. A retrospective study of 103 patients of whom 31 received adjuvant radiotherapy, suggested a survival advantage from this treatment (47). However, efficacy has not been consistently reported (48).

Chemotherapy: There are no randomised trials to guide clinical practice. The majority of patients with stage I disease have an excellent prognosis and will not require adjuvant treatment following surgical resection (46). However, for patients with poor prognosis factors such as large tumour size, high mitotic activity-index or ruptured tumours, adjuvant chemotherapy is commonly considered. BEP is the most accepted regimen in this setting (16), as well as for recurrent disease that is refractory to hormone therapy (46, 49). The potential activity of taxanes has been studied in this disease (50) and the combination of carboplatin and paclitaxel, is not unreasonable. Reported response rates to chemotherapeutic regimens are summarized in Table III.

Hormonal therapy: Hormone treatment is a logical treatment for advanced GrCT, given their frequent oestrogen dependence and usually indolent course (51). Bone density monitoring is indicated for patients receiving aromatase inhibitors, as is the standard of care in breast cancer treatment. A recent systematic review of hormonal therapy for GrCT reported a pooled response rate of $71 \%$ and aromatase inhibitors appear to be the most effective agents, with no reported responses to tamoxifen (52). The role of anastrozole in GrCTs is being assessed in the international multicenter phase II PARAGON trial (ANZGOG 0903), run by the Australia New Zealand Gynaecological Oncology Group. At present, there are no data to support the use of hormone therapy in the adjuvant setting. Available data for hormonal therapy are summarized in Table IV. 
Prognosis: The prognosis for patients with JGrCT is more favourable than for the adult-type, and recurrences are observed almost exclusively within 3 years of operation (53).

The stage at diagnosis is the most important determinant of prognosis for GrCT. The 5-year survival rate for patients with stage I is in excess of $90 \%$ (35). Tumour size has been reported to be prognostic but this has not been consistently reported (44). Unsurprisingly, poorly differentiated diffuse or sarcomatoid type GrCT is associated with poorer outcome. Nuclear atypia and increased mitoses have also been suggested as predictors of recurrence (44). Conflicting results have been reported regarding the prognostic impact of p53 overexpression and $\mathrm{Ki}-67$, where some investigators have reported these as adverse prognostic factors (54), while others reported no association with outcome (55).

\section{SLCTs}

Common to other NEOC, SLCTs are also usually confined to one ovary. They occur most frequently in the third and fourth decades, with $75 \%$ of cases occurring in women aged less than 40 years. SLCTs are characterised by the presence of testicular structures that produce androgens, therefore virilisation is present in $70-85 \%$ of patients (56).

Pathology. These are most commonly well- or moderately differentiated tumours, comprising uncontrolled proliferation of tubules lined by Sertoli cells with intervening nests of Leydig cells (57). Leydig cells are typically found in clusters in interstitial stroma as polygonal cells with well-defined margins, centric nuclei, prominent nucleoli, and eosinophilic cytoplasm. Mesenchymal heterologous elements are present in $22 \%$ of SLCTs and, rarely, these can mimic aggressive tumours such as rhabdomyosarcomas (58). Usually, SLCTs stain positively for inhibin, calretinin, Wilm's tumour 1 and CD56 (59), and negatively for EMA (60).

Treatment. Surgery is key to both the diagnosis and treatment of SLCT. Usually, fertility-sparing surgery with USO is sufficient, but in postmenopausal patients, or those with more radiologically advanced disease, cytoreductive surgery with TAH/BSO is appropriate. Lymph node metastases are rare; therefore lymphadenectomy may be safely omitted during staging surgery (61).

There is no standard adjuvant therapy for SLCTs, and adjuvant chemotherapy is not usually recommended for stage IA-1B disease due to the excellent prognosis with surgery alone (62). For patients with grade 2-3 disease, advanced stage or heterologous elements, adjuvant BEP chemotherapy may be considered. The BEP regimen is active in recurrent or incompletely resected SLCT, but does not offer durable remissions (63). Taxanes may be an effective alternative, with less toxicity compared to BEP in a retrospective study (50).
Prognosis. Tumour stage and grade are the most consistently reported prognostic factors for SLCT. Interestingly, differentiation correlates with age, where poorly differentiated tumours occur at a lower median age than well-differentiated tumours. Relapse in SLCT is usually early; two-thirds of relapses occur within 1 year of diagnosis and only $7 \%$ of relapses occur after 5 years. The abdominal cavity and retroperitoneal nodes are the most common sites of recurrent disease (64).

\section{Very Rare Ovarian Tumours}

There are several rare malignant ovarian tumours that together comprise $\sim 0.1 \%$ of ovarian malignancies (15). These include small cell carcinomas (hypercalcaemic and non-hypercalcaemic types), and ovarian sarcomas.

\section{Small-cell carcinomas}

Small-cell carcinoma of the ovary (SCCO), hypercalcaemic type, occurs at a median age of 24 years, and is usually (but not always) accompanied by hypercalcaemia at diagnosis (7). These tumours rapidly enlarge with local pressure symptoms at presentation and are typically unilateral, therefore the main differential diagnosis is GCT. Despite unilateral ovarian disease, these are commonly advanced (stage 3 ) at diagnosis (65).

The non-hypercalcaemic type of SCCO are analogous to neuroendocrine, pulmonary-type small cell tumours. These typically occur in older, postmenopausal patients and follow a similar clinical course to small-cell lung cancer.

Pathology. Hypercalcaemic-type SCCO has been recently sequenced and confirmed to be a malignant rhabdoid tumour by virtue of consistent deleterious mutations in SMARCA4 (SWI/SNF-related, matrix-associated, actin-dependent regulator of chromatin, subfamily a, member 4), a chromatinremodelling gene (66). Although these tumours resemble neuroendocrine small-cell tumours morphologically, these are now recognized to be a distinct clinical and pathological entity.

Like small-cell lung cancer, pulmonary-type SCCO is characterised histologically by the presence of small round (or spindle-shaped) cells, with sparse cytoplasm and hyperchromatic nuclei. Pulmonary-type SCCO may grow in pre-existing malignant or benign ovarian tumours, such as endometrioid carcinoma and Brenner tumour (8).

Treatment. For hypercalcaemic-type SCCO tumours, no prospective studies have been performed and treatment decisions are therefore based on case series. A multimodality treatment approach is recommended including debulking surgery to relieve symptoms and assess the extent of disease followed by chemotherapy and possibly 
radiotherapy. As the disease is unilateral in $99 \%$ of cases, fertility-sparing surgery with unilateral oophorectomy and debulking of visible disease is reasonable. In the largest case series, reported by Harrison et al. (67), all patients received adjuvant platinum-based chemotherapy, irrespective of stage. Common regimens include BEP, carboplatin and paclitaxel, and carboplatin plus etoposide. Of interest, most of the longterm survivors also received adjuvant radiotherapy either following or concurrently with chemotherapy: Five out of seven patients with stage 1 disease who received radiotherapy were alive beyond 50 months. In addition to the primary treatment of the disease, control of hypercalcemia may require aggressive hydration and intravenous bisphosphonates. Hypercalcaemia typically resolves after removal of the primary tumour.

For pulmonary-type SCCO, primary surgery was recommended for operable disease in a recent consensus statement, followed by adjuvant carboplatin and etoposide (68). Arguably, the treatment of these aggressive cancer s should be extrapolated from the more common small-cell lung cancers, with primary chemotherapy with carboplatin and etoposide, and responses consolidated with chemoradiation if the disease is loco-regional. However, there is no evidence base for the optimal treatment of these rare cancers, which are associated with a very poor prognosis.

Prognosis. These are aggressive malignancies with a dismal prognosis. For hypercalcaemic-type SCCO, the majority of patients relapse despite the multi-modality treatment and the 5 -year overall survival rate for all stages is approximately $10 \%$ (65). For patients with stage III disease, the median survival is just 6 months (67). Age over 30 years, normal preoperative calcium at presentation, tumour size less than $10 \mathrm{~cm}$, and histological absence of large cells appear to be favourable prognostic features in stage 1A disease (69).

\section{Sarcomas}

Primary ovarian/fallopian tube sarcomas are rare, and treated according to their histological sub-type, which may include angiosarcoma, fibrosarcoma, leiomyosarcoma, liposarcoma and osteosarcoma. These tumours should be managed by specialist sarcoma units according to their sub-type, rather than their ovarian site of origin. This will normally comprise aggressive surgery for localised cancers and palliative chemotherapy for metastatic disease.

Malignant mixed mesodermal tumours (MMMTs, previously known as carcinosarcomas) of the ovary are rare, aggressive cancers, occurring most commonly in postmenopausal women. Their presentation is similar to that of epithelial ovarian cancer, although few patients present with disease confined to the ovary and many will have visceral metastases at presentation. The epithelial component may be endometrioid, serous, clear cell, or solid (transitional) types. The concomitant sarcomatous components are either of homologous type, usually high-grade sarcomas, leiomyosarcoma, or endometrial stromal sarcoma. However, heterologous types such as rhabdomyosarcomas, chondrosarcoma and, less commonly, liposarcoma may also be present. Any of these patterns may overgrow and obliterate other components. These tumours are treated in the same way as high-risk epithelial ovarian cancer but their prognosis is usually poor (70).

\section{Conclusions and Future Directions}

NEOC are a heterogenous group of rare tumours that affect mainly young patients. Whilst patients with GCT have an excellent prognosis, with cure rates approaching $100 \%$ for those with early-stage disease, the 1-year survival for those with SCCO is just $50 \%$. SCSTs are generally more indolent with an excellent short-term prognosis, but carry a significant risk of late relapse.

There is a genuine need for more pre-clinical work on these rare diseases to allow investigation of novel drug targets which could lead to clinical trials. Due to the rarity of NEOC, randomised trials for assessing the relative benefits of different treatment modalities are extremely challenging, but could be achieved with international cooperation.

\section{Conflicts of Interest}

The Authors declare no conflict of interest.

\section{Acknowledgements}

Dr. Boussios is clinical research fellow funded by the Medical School of the University of Ioannina, Greece.

\section{References}

1 Tavassoli FA and Deville P: Pathology and Genetics of Tumours of the Breast and Female Genital Organs. Lyon, France: International Agency for Research on Cancer, pp. 163-179, 2003.

2 Lee-Jones L: Ovary: Germ cell tumors. Atlas Genet Cytogenet Oncol Haematol, 2003, available at http://atlasgenetics oncology.org/Tumors/OvarianGermCellID5067.html

3 Pectasides D, Pectasides E and Psyrri A: Granulosa cell tumor of the ovary. Cancer Treat Rev 34: 1-12, 2008.

4 Schumer ST and Cannistra SA: Granulosa cell tumor of the ovary. J Clin Oncol 21: 1180-1189, 2003.

5 Koulouris CR and Penson RT: Ovarian stromal and germ cell tumors. Semin Oncol 36: 126-136, 2009.

6 Parkinson CA, Hatcher HM and Ajithkumar TV: Management of malignant ovarian germ cell tumors. Obstet Gynecol Surv 66: 507-514, 2011.

7 Young RH, Goodman A, Penson RT, Russell AH, Uppot RN and Tambouret RH: Case records of the Massachusetts General Hospital. Case 8-2010. A 22-year-old woman with hypercalcemia and a pelvic mass. N Engl J Med 362: 1031-1040, 2010. 
8 Eichhorn JH, Young RH and Scully RE: Primary ovarian small cell carcinoma of pulmonary type. A clinicopathologic, immunohistologic, and flow cytometric analysis of 11 cases. Am J Surg Pathol 16: 926-938, 1992.

9 Zalel Y, Piura B, Elchalal U, Czernobilsky B, Antebi S and Dgani R: Diagnosis and management of malignant germ cell ovarian tumors in young females. Int J Gynaecol Obstet 55: 110, 1996.

10 Gershenson DM, del Junco G, Silva EG, Copeland LJ, Wharton JT and Rutledge FN: Immature teratoma of the ovary. Obstet Gynecol 68: 624-629, 1986.

11 Gershenson DM: Management of ovarian germ cell tumors. J Clin Oncol 2007 25: 2938-2943, 2007.

12 Kodama M, Grubbs BH, Blake EA, Cahoon SS, Murakami R, Kimura $\mathrm{T}$ and Matsuo K: Feto-maternal outcomes of pregnancy complicated by ovarian malignant germ cell tumor: a systematic review of literature. Eur J Obstet Gynecol Reprod Biol 181: 145156,2014

13 Cao D, Guo S, Allan RW, Molberg KH and Peng Y: SALL4 is a novel sensitive and specific marker of ovarian primitive germ cell tumors and is particularly useful in distinguishing yolk sac tumor from clear cell carcinoma. Am J Surg Pathol 33: 894-904, 2009.

14 Ushiku T, Shinozaki A, Shibahara J, Iwasaki Y, Tateishi Y, Funata $\mathrm{N}$ and Fukayama M: SALL4 represents fetal gut differentiation of gastric cancer, and is diagnostically useful in distinguishing hepatoid gastric carcinoma from hepatocellular carcinoma. Am J Surg Pathol 34: 533-540, 2010.

15 Scully RE, Young RH and Clement PB: Tumors of the Ovary, Maldeveloped Gonads, Fallopian Tube, and Broad Ligament. Third Series, Fascicle 23. Washington, DC: Armed Forces Institute of Pathology, 1998.

16 Colombo N, Peiretti M, Garbi A, Carinelli S, Marini C and Sessa C; ESMO Guidelines Working Group: Non-epithelial ovarian cancer: ESMO Clinical Practice Guidelines for diagnosis, treatment and follow-up. Ann Oncol 23: vii20-26, 2012.

17 Billmire DF, Cullen JW, Rescorla FJ, Davis M, Schlatter MG, Olson TA, Malogolowkin MH, Pashankar F, Villaluna D, Krailo $\mathrm{M}$, Egler RA, Rodriguez-Galindo $\mathrm{C}$ and Frazier AL: Surveillance after initial surgery for pediatric and adolescent girls with stage I ovarian germ cell tumors: report from the Children's Oncology Group. J Clin Oncol 32: 465-470, 2014.

18 Smith HO, Berwick M, Verschraegen CF, Wiggins C, Lansing L, Muller CY and Qualls CR: Incidence and survival rates for female malignant germ cell tumors. Obstet Gynecol 107: 1075-1085, 2006.

19 Koi C, Kurita T, Kagami S, Matsuyaya A and Hachisuga T: A case of ovarian yolk sac tumor associated with endometrioid adenocarcinoma. Gynecol Oncol Case Rep 9: 11-14, 2014.

20 Maeda D, Ota S, Takazawa Y, Aburatani H, Nakagawa S, Yano $\mathrm{T}$, Taketani $\mathrm{Y}$, Kodama $\mathrm{T}$ and Fukayama M: Glypican-3 expression in clear cell adenocarcinoma of the ovary. Mod Pathol 22: 824-832, 2009.

21 Kurman RJ and Norris HJ: Malignant germ cell tumors of the ovary. Hum Pathol 8: 551-564, 1977.

22 National Comprehensive Cancer Network. NCCN Clinical Practice Guidelines in Oncology: Ovarian Cancer. URL: http:// www.nccn.org/professionals/physician_gls/f_guidelines.asp.

23 Patterson DM, Murugaesu N, Holden L, Seckl MJ and Rustin GJ: A review of the close surveillance policy for stage I female germ cell tumors of the ovary and other sites. Int $\mathrm{J}$ Gynecol Cancer 18: 43-50, 2008.
24 Williams SD, Blessing JA, DiSaia PJ, Major FJ, Ball HG 3rd and Liao SY: Second-look laparotomy in ovarian germ cell tumors: the gynecologic oncology group experience. Gynecol Oncol 52: 287-291, 1994.

25 Bentivegna E, Azaïs H, Uzan C, Leary A, Pautier P, Gonthier C, Genestie C, Balleyguier C, Lhomme C, Duvillard P, Morice P and Gouy S: surgical outcomes after debulking surgery for intraabdominal ovarian growing teratoma syndrome: Analysis of 38 cases. Ann Surg Oncol 22: S964-970, 2015.

26 Dimopoulos MA, Papadimitriou C, Hamilos G, Efstathiou E, Vlahos G, Rodolakis A, Aravantinos G, Kalofonos H, Kouroussis C, Gika D, Skarlos D and Bamias A: Treatment of ovarian germ cell tumors with a 3-day bleomycin, etoposide, and cisplatin regimen: a prospective multicenter study. Gynecol Oncol 95: 695-700, 2004.

27 Kondagunta GV, Bacik J, Donadio A, Bajorin D, Marion S, Sheinfeld J, Bosl GJ and Motzer RJ: Combination of paclitaxel, ifosfamide, and cisplatin is an effective second-line therapy for patients with relapsed testicular germ cell tumors. J Clin Oncol 23: 6549-6555, 2005.

28 Billmire D, Vinocur C, Rescorla F, Cushing B, London W, Schlatter M, Davis M, Giller R, Lauer S and Olson T; Children's Oncology Group (COG): Outcome and staging evaluation in malignant germ cell tumors of the ovary in children and adolescents: an intergroup study. J Pediatr Surg 39: 424-429, 2004.

29 Solheim O, Gershenson DM, Tropé CG, Rokkones E, Sun CC, Weedon-Fekjaer $\mathrm{H}$ and Fosså SD: Prognostic factors in malignant ovarian germ cell tumours (The Surveillance, Epidemiology and End Results experience 1978-2010). Eur J Cancer 50: 1942-1950, 2014.

30 Solheim O, Tropé CG, Rokkones E, Kærn J, Paulsen T, Salvesen HB, Hagen B, Vereide AB and Fosså SD: Fertility and gonadal function after adjuvant therapy in women diagnosed with a malignant ovarian germ cell tumor (MOGCT) during the "cisplatin era". Gynecol Oncol 136: 224-229, 2015.

31 Zanetta G, Bonazzi C, Cantù M, Binidagger S, Locatelli A, Bratina $G$ and Mangioni C: Survival and reproductive function after treatment of malignant germ cell ovarian tumors. J Clin Oncol 19: 1015-1020, 2001.

32 Sklar CA, Mertens AC, Mitby P, Whitton J, Stovall M, Kasper C, Mulder J, Green D, Nicholson HS, Yasui Y and Robison LL: Premature menopause in survivors of childhood cancer: a report from the childhood cancer survivor study. J Natl Cancer Inst 98 : 890-896, 2006.

33 Del Mastro L, Boni L, Michelotti A, Gamucci T, Olmeo N, Gori S, Giordano M, Garrone O, Pronzato P, Bighin C, Levaggi A, Giraudi S, Cresti N, Magnolfi E, Scotto T, Vecchio C and Venturini M: Effect of the gonadotropin-releasing hormone analogue triptorelin on the occurrence of chemotherapy-induced early menopause in premenopausal women with breast cancer: a randomized trial. JAMA 306: 269-276, 2011.

34 Nichols CR, Breeden ES, Loehrer PJ, Williams SD and Einhorn LH: Secondary leukemia associated with a conventional dose of etoposide: review of serial germ cell tumor protocols. J Natl Cancer Inst 85: 36-40, 1993.

35 Zhang M, Cheung MK, Shin JY, Kapp DS, Husain A, Teng NN, Berek JS, Osann K and Chan JK: Prognostic factors responsible for survival in sex cord stromal tumors of the ovary--an analysis of 376 women. Gynecol Oncol 104: 396-400, 2007. 
36 vanMeurs HS, Bleeker MC, van der Velden J, Overbeek LI, Kenter GG and Buist MR: The incidence of endometrial hyperplasia and cancer in 1031 patients with a granulosa cell tumor of the ovary: long-term follow-up in a population-based cohort study. Int J Gynecol Cancer 23: 1417-1422, 2013.

37 Gittleman AM, Price AP, Coren C, Akhtar M, Donovan V and Katz DS: Juvenile granulosa cell tumor. Clin Imaging 27: 221224, 2003.

38 McCluggage WG: Immunoreactivity of ovarian juvenile granulosa cell tumours with epithelial membrane antigen. Histopathology 46: 235-236, 2005.

39 Jamieson S and Fuller PJ: Management of granulosa cell tumour of the ovary. Curr Opin Oncol 20: 560-564, 2008.

40 Sekkate S, Kairouani M, Serji B, Tazi A, Mrabti H, Boutayeb S and Errihani H: Ovarian granulosa cell tumors: a retrospective study of 27 cases and a review of the literature. World J Surg Oncol 2013 11: 142, 2013

41 Shah SP, Köbel M, Senz J, Morin RD, Clarke BA, Wiegand KC, Leung G, Zayed A, Mehl E, Kalloger SE, Sun M, Giuliany R, Yorida E, Jones S, Varhol R, Swenerton KD, Miller D, Clement PB, Crane C, Madore J, Provencher D, Leung P, DeFazio A, Khattra J, Turashvili G, Zhao Y, Zeng T, Glover JN, Vanderhyden B, Zhao C, Parkinson CA, Jimenez-Linan M, Bowtell DD, Mes-Masson AM, Brenton JD, Aparicio SA, Boyd N, Hirst M, Gilks CB, Marra M and Huntsman DG: Mutation of FOXL2 in granulosa-cell tumors of the ovary. N Eng1 J Med 360: 2719-2729, 2009.

42 Rey RA, Lhommé C, Marcillac I, Lahlou N, Duvillard P, Josso $\mathrm{N}$ and Bidart JM: Antimüllerian hormone as a serum marker of granulosa cell tumors of the ovary: comparative study with serum alpha-inhibin and estradiol. Am J Obstet Gynecol 174: 958-965, 1996.

43 Robertson DM, Cahir N, Burger HG, Mamers P and Groome N: Inhibin forms in serum from postmenopausal women with ovarian cancers. Clin Endocrinol (Oxf) 50: 381-386, 1999.

44 Ranganath R, Sridevi V, Shirley SS and Shantha V: Clinical and pathologic prognostic factors in adult granulosa cell tumors of the ovary. Int J Gynecol Cancer 18: 929-933, 2008.

45 Wolf JK, Mullen J, Eifel PJ, Burke TW, Levenback C and Gershenson DM: Radiation treatment of advanced or recurrent granulosa cell tumor of the ovary. Gynecol Oncol 73: 35-41, 1999.

46 Savage P, Constenla D, Fisher C, Shepherd JH, Barton DP, Blake P and Gore ME: Granulosa cell tumours of the ovary: demographics, survival and the management of advanced disease. Clin Oncol 10: 242-245, 1998.

47 Hauspy J, Beiner ME, Harley I, Rosen B, Murphy J, Chapman W, Le LW, Fyles A and Levin W: Role of adjuvant radiotherapy in granulosa cell tumors of the ovary. Int J Radiat Oncol Biol Phys 79: 770-774, 2011.

48 E C, Samant R, Fung MF, Le T, Hopkins L and Senterman M: Palliative radiotherapy for recurrent granulosa cell tumor of the ovary: a report of 3 cases with radiological evidence of response. Gynecol Oncol 102: 406-410, 2006.

49 Zambetti M, Escobedo A, Pilotti S and De Palo G: cisplatinum/vinblastine/bleomycin combination chemotherapy in advanced or recurrent granulosa cell tumors of the ovary. Gynecol Oncol 36: 317-320, 1990.

50 Brown J, Shvartsman HS, Deavers MT, Ramondetta LM, Burke TW, Munsell MF and Gershenson DM: The activity of taxanes compared with bleomycin, etoposide, and cisplatin in the treatment of sex cord-stromal ovarian tumors. Gynecol Oncol 97: 489-496, 2005.

51 Alexiadis M, Eriksson N, Jamieson S, Davis M, Drummond AE, Chu S, Clyne CD, Muscat GE and Fuller PJ: Nuclear receptor profiling of ovarian granulosa cell tumors. Horm Cancer 2: 157$169,2011$.

52 van Meurs HS, van Lonkhuijzen LR, Limpens J, van der Velden $\mathrm{J}$ and Buist MR: Hormone therapy in ovarian granulosa cell tumors: a systematic review. Gynecol Oncol 134: 196-205, 2014.

53 Roth LM: Recent advances in the pathology and classification of ovarian sex cord-stromal tumors. Int J Gynecol Pathol 25: 199-215, 2006.

54 Jurić $\mathrm{G}$, Zarković $\mathrm{N}$, Nola $\mathrm{M}$, Tillian $\mathrm{M}$ and Jukić $\mathrm{S}$ : The value of cell proliferation and angiogenesis in the prognostic assessment of ovarian granulosa cell tumors. Tumori 87: 47-53, 2001.

55 Gebhart JB, Roche PC, Keeney GL, Lesnick TG and Podratz $\mathrm{KC}$ : Assessment of inhibin and p53 in granulosa cell tumors of the ovary. Gynecol Oncol 77: 232-236, 2000.

56 Kurtz JE, Jaeck D, Maloisel F, Jung GM, Chenard MP and Dufour P: Combined modality treatment for malignant transformation of a benign ovarian teratoma. Gynecol Oncol 73: 319-321, 1999.

57 Nouriani M, Felix JC and Dubeau L: Histogenesis and histopathological characteristics of Sertoli-Leydig cell tumors. CME J Gynecol Oncol 7: 114-120, 2002.

58 Rekhi B, Karpate A, Deodhar KK and Chinoy RF: Metastatic rhabdomyosarcomatous elements, mimicking a primary sarcoma, in the omentum, from a poorly differentiated ovarian SertoliLeydig cell tumor in a young girl: an unusual presentation with a literature review. Indian J Pathol Microbiol 52: 554-558, 2009.

59 McCluggage WG, McKenna $\mathrm{M}$ and McBride HA: CD56 is a sensitive and diagnostically useful immunohistochemical marker of ovarian sex cord-stromal tumors. Int J Gynecol Pathol 26: 322-327, 2007

60 McCluggage WG and Young RH: Immunohistochemistry as a diagnostic aid in the evaluation of ovarian tumors. Semin Diagn Pathol 22: 3-32, 2005.

61 Brown J, Sood AK, Deavers MT, Milojevic L and Gershenson DM: Patterns of metastasis in sex cord-stromal tumors of the ovary: Can routine staging lymphadenectomy be omitted? Gynecol Oncol 113: 86-90, 2009.

62 Ray-Coquard I, Brown J, Harter P, Provencher DM, Fong PC, Maenpaa J, Ledermann JA, Emons G, Rigaud DB, Glasspool RM, Mezzanzanica D and Colombo N: Gynecologic Cancer InterGroup (GCIG) consensus review for ovarian sex cord stromal tumors. Int J Gynecol Cancer 24: S42-47, 2014.

63 Colombo N, Parma G, Zanagnolo V and Insinga A: Management of ovarian stromal cell tumors. J Clin Oncol 25: 2944-2951, 2007.

64 Lantzsch T, Stoerer S, Lawrenz K, Buchmann J, Strauss HG and Koelbl H: Sertoli-Leydig cell tumor. Arch Gynecol Obstet 264: 206-208, 2001

65 Dykgraaf RH, de Jong D, van Veen M, Ewing-Graham PC, Helmerhorst TJ and van der Burg ME: Clinical management of ovarian small-cell carcinoma of the hypercalcemic type: a proposal for conservative surgery in an advanced stage of disease. Int J Gynecol Cancer 19: 348-353, 2009.

66 Foulkes WD, Clarke BA, Hasselblatt M, Majewski J, Albrecht $\mathrm{S}$ and McCluggage WG: No small surprise - small cell carcinoma of the ovary, hypercalcaemic type, is a malignant rhabdoid tumour. J Pathol 233: 209-214, 2014. 
67 Harrison ML, Hoskins P, du Bois A, Quinn M, Rustin GJ, Ledermann JA, Baron-Hay S and Friedlander ML: Small cell of the ovary, hypercalcemic type - analysis of combined experience and recommendation for management. A GCIG study. Gynecol Oncol 100: 233-238, 2006.

68 Reed NS, Pautier P, Åvall-Lundqvist E, Choi CH, du Bois A, Friedlander M, Fyles A, Kichenadasse G, Provencher DM and Ray-Coquard I: Gynecologic Cancer Inter Group (GCIG) consensus review for ovarian small cell cancers. Int J Gynecol Cancer 24: S30-34, 2014.

69 Young RH, Oliva E and Scully RE: Small cell carcinoma of the ovary, hypercalcemic type. A clinicopathological analysis of 150 cases. Am J Surg Pathol 18: 1102-1116, 1994.

70 Berton-Rigaud D, Devouassoux-Shisheboran M, Ledermann JA, Leitao MM, Powell MA, Poveda A, Beale P, Glasspool RM, Creutzberg CL, Harter P, Kim JW, Reed NS and Ray-Coquard I: Gynecologic Cancer InterGroup (GCIG) consensus review for uterine and ovarian carcinosarcoma. Int J Gynecol Cancer 24: S55-60, 2014.

71 Gershenson DM, Copeland LJ, Kavanagh JJ, Stringer CA, Saul PB and Wharton JT: Treatment of metastatic stromal tumors of the ovary with cisplatin, doxorubicin, and cyclophosphamide. Obstet Gynecol 70: 765-769, 1987.

72 Pecorelli S, Wagenaar HC, Vergote IB, Curran D, Beex LV, Wiltshaw E and Vermorken JB: Cisplatin (P), vinblastine (V) and bleomycin (B) combination chemotherapy in recurrent or advanced granulosa(-theca) cell tumours of the ovary. An EORTC Gynaecological Cancer Cooperative Group study. Eur J Cancer 35: 1331-1337, 1999.

73 Pectasides D, Alevizakos $\mathrm{N}$ and Athanassiou AE: Cisplatincontaining regimen in advanced or recurrent granulosa cell tumours of the ovary. Ann Oncol 3: 316-318, 1992.

74 Gershenson DM, Morris M, Burke TW, Levenback C, Matthews $\mathrm{CM}$ and Wharton JT: Treatment of poor-prognosis sex cordstromal tumors of the ovary with the combination of bleomycin, etoposide, and cisplatin. Obstet Gynecol 87: 527-531, 1996.

75 Homesley HD, Bundy BN, Hurteau JA and Roth LM: Bleomycin, etoposide, and cisplatin combination therapy of ovarian granulosa cell tumors and other stromal malignancies: A Gynecologic Oncology Group study. Gynecol Oncol 72: 131-137, 1999.

76 Al-Badawi IA, Brasher PM, Ghatage P, Nation JG, Schepansky A and Stuart GC: Postoperative chemotherapy in advanced ovarian granulosa cell tumors. Int J Gynecol Cancer 12: 119-123, 2002.

77 Uygun K, Aydiner A, Saip P, Basaran M, Tas F, Kocak Z, Dincer $\mathrm{M}$ and Topuz E: Granulosa cell tumor of the ovary: retrospective analysis of 45 cases. Am J Clin Oncol 26: 517-521, 2003.

78 Pectasides D, Papaxoinis G, Fountzilas G, Aravantinos G, Pectasides E, Mouratidou D, Economopoulos T and Andreadis $\mathrm{Ch}$ : Adult granulosa cell tumors of the ovary: a clinicopathological study of 34 patients by the Hellenic Cooperative Oncology Group (HeCOG). Anticancer Res 28: 1421-1427, 2008.

79 Pautier P, Gutierrez-Bonnaire M, Rey A, Sillet-Bach I, Chevreau C, Kerbrat $\mathrm{P}$, Morice $\mathrm{P}$, Duvillard $\mathrm{P}$ and Lhommé $\mathrm{C}$ : Combination of bleomycin, etoposide, and cisplatin for the treatment of advanced ovarian granulosa cell tumors. Int $\mathrm{J}$ Gynecol Cancer 18: 446-452, 2008.

80 van Meurs HS, Buist MR, Westermann AM, Sonke GS, Kenter GG and van der Velden J: Effectiveness of chemotherapy in measurable granulosa cell tumors: a retrospective study and review of literature. Int J Gynecol Cancer 24: 496-505, 2014.
81 Malik ST and Slevin ML: Medroxyprogesterone acetate (MPA) in advanced granulosa cell tumours of the ovary - a new therapeutic approach? Br J Cancer 63: 410-411, 1991.

82 Isaacs R, Forgeson $\mathrm{G}$ and Allan S: Progestagens for granulosa cell tumours of the ovary. Br J Cancer 65: 140, 1992.

83 Kauppila A, Bangah M, Burger $\mathrm{H}$ and Martikainen $\mathrm{H}$ : $\mathrm{GnRH}$ agonist analog therapy in advanced/recurrent granulosa cell tumors: further evidence of a role of inhibin in monitoring response to treatment. Gynecol Endocrinol 6: 271-274, 1992.

84 Maxwell GL, Soisson AP and Miles P: Failure of gonadotropin releasing hormone therapy in patients with metastatic ovarian sex cord stromal tumors. Oncology 51: 356-359, 1994.

85 Fishman A, Kudelka AP, Tresukosol D, Edwards CL, Freedman RS, Kaplan AL, Girtanner RE, Kavanagh JJ. Leuprolide acetate for treating refractory or persistent ovarian granulosa cell tumor. J Reprod Med 41: 393-396, 1996.

86 Briasoulis E, Karavasilis V and Pavlidis N: Megestrol activity in recurrent adult type granulosa cell tumour of the ovary. Ann Oncol 8: 811-812, 1997.

87 Crew KD, Cohen MH, Smith DH, Tiersten AD, Feirt NM and Hershman DL: Long natural history of recurrent granulosa cell tumor of the ovary 23 years after initial diagnosis: a case report and review of the literature. Gynecol Oncol 96: 235-240, 2005.

88 Ameryckx L, Fatemi HM, De Sutter P and Amy JJ : GnRH antagonist in the adjuvant treatment of a recurrent ovarian granulosa cell tumor: a case report. Gynecol Oncol 99: 764-766, 2005.

89 Hardy RD, Bell JG, Nicely CJ and Reid GC: Hormonal treatment of a recurrent granulosa cell tumor of the ovary: case report and review of the literature. Gynecol Oncol 96: 865-869, 2005.

90 Freeman SA, Modesitt SC. Anastrozole therapy in recurrent ovarian adult granulosa cell tumors: a report of 2 cases. Gynecol Oncol 103: 755-758, 2006.

91 Korach J, Perri T, Beiner M, Davidzon T, Fridman E and BenBaruch G: Promising effect of aromatase inhibitors on recurrent granulosa cell tumors. Int J Gynecol Cancer 19: 830-833, 2009.

92 Kim HJ, Lee SC, Bae SB, Kwon KW, Kim CK, Lee NS, Lee KT, Won JH, Hong DS and Park HS: GnRH agonist therapy in a patient with recurrent ovarian granulosa cell tumors. J Korean Med Sci 24: 535-538, 2009.

93 Teoh D, Freedman R and Soliman PT: Nearly 30 years of treatment for recurrent granulosa cell tumor of the ovary: a case report and review of the literature. Case Rep Oncol 3: 14-18, 2010.

94 Abdul Munem A, Al-Bahrani B, Mehdi I, Kamona A and Nadas AM: Aromatase inhibitors - a viable option for recurrent granulosa cell tumour of ovary: overview and case report. J Pak Med Assoc 62: 505-507, 2012.

95 Alhilli MM, Long HJ, Podratz KC and Bakkum-Gamez JN: Aromatase inhibitors in the treatment of recurrent ovarian granulosa cell tumors: brief report and review of the literature. J Obstet Gynaecol Res 38: 340-344, 2012.

96 Keskin S, Bengisu E, Tuzlali S and Aydiner A: Complete response in a patient with granulosa cell tumor treated with a combination of leuprolide and tamoxifen. Onkologie 35: 451-453, 2012.

97 Kourie HR, Kattan J, Antoun J and Sleilaty F: Letrozole efficacy in the treatment of granulosa cell tumor of the ovary: a case report. Onkologie 36: 498-500, 2013.

Received September 6, 2016

Revised September 21, 2016

Accepted September 23, 2016 